\title{
Monitoring user activities in smart home environments
}

\author{
Sajid Hussain • Senol Zafer Erdogan • Jong Hyuk Park
}

Published online: 30 July 2008

(C) Springer Science + Business Media, LLC 2008

\section{Erratum to: Inf Syst Front}

\section{DOI 10.1007/s10796-008-9124-1}

The original version of this article unfortunately contained a mistake. The spelling of the Senol Zafer Erdogen's name was incorrect.

The online version of the original article can be found at http://dx.doi. org/10.1007/s10796-008-9124-1.

S. Hussain $(\square)$

Jodrey School of Computer Science, Acadia University,

Wolfville, Nova Scotia, Canada

e-mail: sajid.hussain@acadiau.ca

\section{S. Z. Erdogan}

Faculty of Engineering, Maltepe University,

Istanbul, Turkey

e-mail: senole@maltepe.edu.tr

J. H. Park

Department of Computer Science and Engineering,

Kyungnam University,

Masan, Korea

e-mail: parkjonghyuk1@hotmail.com 